\title{
Estudo epidemiológico de avaliação do aumento da incidência de arboviroses em consequência ao rompimento de barragens em Minas Gerais, Brasil
}

\author{
Epidemiological study of evaluation of increased incidence of arboviroses as a result of dam \\ breaking in Minas Gerais, Brazil \\ Estudio epidemiológico de evaluación del aumento de la incidencia de arbovirosis como resultado \\ de la rotura de la presa en Minas Gerais, Brasil
}

Recebido: 27/12/2020 | Revisado: 28/12/2020 | Aceito: 01/01/2021 | Publicado: 04/01/2021

\author{
Emily Rafaela Machado de Souza \\ ORCID: https://orcid.org/0000-0002-1809-8355 \\ Universidade da Amazônia, Brasil \\ E-mail: emily.souza@icb.ufpa.br \\ Alexa Mamedio Nogueira Oliveira \\ ORCID: https://orcid.org/0000-0001-7062-7966 \\ Universidade da Amazônia, Brasil \\ E-mail: aleoliveira1529@gmail.com \\ Jonilson Willamos Alho de Carvalho \\ ORCID: https://orcid.org/0000-0002-7769-4130 \\ Universidade da Amazônia, Brasil \\ E-mail: jonilsonalho8010@gmail.com \\ Murilo Tavares Amorim \\ ORCID: https://orcid.org/0000-0002-9769-2183 \\ Centro Universitário Fibra, Brasil \\ E-mail: muriloamorimbio@gmail.com \\ Francisco Canindé Ferreira de Luna \\ ORCID: https://orcid.org/0000-0002-4688-4548 \\ Universidade Federal do Pará, Brasil \\ E-mail: lunafcf@gmail.com \\ Dirceu Costa dos Santos \\ ORCID: https://orcid.org/0000-0002-0334-3899 \\ Universidade da Amazônia, Brasil \\ E-mail: direção.parqueshopping@unama.br \\ Gustavo Moraes Holanda \\ ORCID: https://orcid.org/0000-0001-6730-9254 \\ Universidade da Amazônia, Brasil \\ E-mail: holandagm@gmail.com
}

\begin{abstract}
Resumo
Objetivo: Realizar um levantamento bibliográfico e relatórios do aumento de casos de Febre Amarela, Chickungunya, Dengue e Zika após o rompimento das barragens de Mariana e Brumadinho (Minas Gerais). Metodologia: Foi feito um estudo bibliográfico, epidemiológico com artigos, reportagens e busca em plataformas acadêmicas e de boletins do Ministério da Saúde com o intuito de associar o aumento dos casos conforme sua localização de acordo com o período após o rompimento. Resultados: Houve um aumento evidente nos casos de arboviroses logo após o rompimento das barragens em áreas afetadas com o impacto e proximidades. Isso pode ser resultado da movimentação de pessoas e animais após as tragédias, pois com a degradação da área, pessoas foram afetadas de maneira direta e indireta, as que foram afetadas de maneira direta tiveram suas casas destruídas pela lama e as que foram afetadas de maneira indireta podem ter saído da cidade em busca de alternativas de melhora. Também há uma alteração na cadeia alimentar local, algumas populações elevam e outras diminuem, as populações de mosquitos elevam e migram para outras áreas mais populosas em busca de alimento, assim sendo um fator da disseminação de doenças. Conclusão: Observou-se ne que no período de 2015 a 2016 os casos de CHIKV foram os que mais cresceram no Brasil, tendo um aumento de quase 10x, de Febre Amarela e Dengue tendo um aumento de mais ou menos 3x. Os casos de Zika começam a ser notificados em 2015, portanto não é possível determinar se houve um aumento significativo.
\end{abstract}

Palavras-chave: Arbovírus; Arboviroses; Barragens; Meio-ambiente.

\footnotetext{
Abstract

Objective: To carry out a bibliographic survey and reports on the increase in cases of Yellow Fever, Chickungunya, Dengue and Zika after the rupture of the Mariana and Brumadinho dams (Minas Gerais). Methodology: A
} 
bibliographic, epidemiological study was carried out with articles, reports and search in academic platforms and bulletins from the Ministry of Health in order to associate the increase in cases according to their location according to the period after the rupture. Results: There was an evident increase in cases of arboviruses right after the rupture of the dams in areas affected by the impact and proximity. This may be the result of the movement of people and animals after the tragedies, because with the degradation of the area, people were directly and indirectly affected, those who were directly affected had their houses destroyed by mud and those who were affected in a way may have left the city in search of alternatives for improvement. There is also a change in the local food chain, some populations increase and others decrease, mosquito populations increase and migrate to other more populous areas in search of food, thus being a factor in the spread of diseases. Conclusion: It was observed that in the period from 2015 to 2016 the cases of CHIKV were those that grew the most in Brazil, with an increase of almost 10x, of Yellow Fever and Dengue having an increase of more or less $3 \mathrm{x}$. Zika cases begin to be reported in 2015, so it is not possible to determine whether there has been a significant increase.

Keywords: Arboviruses; Arboviruses; Dams; Environment.

\section{Resumen}

Objetivo: Realizar un relevamiento bibliográfico e informes sobre el incremento de casos de Fiebre Amarilla, Chickungunya, Dengue y Zika tras la ruptura de las represas Mariana y Brumadinho (Minas Gerais). Metodología: Se realizó un estudio bibliográfico, epidemiológico con artículos, informes y búsqueda en plataformas académicas y boletines del Ministerio de Salud con el fin de asociar el aumento de casos según su ubicación según el período posterior a la ruptura. Resultados: Hubo un aumento evidente de casos de arbovirus inmediatamente después de la ruptura de las presas en las áreas afectadas por el impacto y la proximidad. Esto puede ser el resultado del movimiento de personas y animales luego de las tragedias, porque con la degradación de la zona, las personas se vieron afectadas directa e indirectamente, los que fueron directamente afectados tuvieron sus casas destruidas por el barro y los que fueron afectados de alguna manera. Puede que haya abandonado la ciudad en busca de alternativas de mejora. También hay un cambio en la cadena alimentaria local, algunas poblaciones aumentan y otras disminuyen, las poblaciones de mosquitos aumentan y migran a otras zonas más pobladas en busca de alimento, siendo así un factor de propagación de enfermedades. Conclusión: Se observó que en el período de 2015 a 2016 los casos de CHIKV fueron los que más crecieron en Brasil, con un aumento de casi 10x, de Fiebre Amarilla y Dengue con un aumento de más o menos 3x. Los casos de Zika comienzan a notificarse en 2015, por lo que no es posible determinar si ha habido un aumento significativo.

Palabras clave: Arbovirus; Arbovirus; Represas; Medio ambiente.

\section{Introdução}

Arbovírus são vírus que possuem parte do seu ciclo e sua transmissão mediada por artrópodes durante o repasto sanguíneo (Avelino, 2017; Lopes, 2014). O mosquito infectado ao se alimentar do sangue, inocula o vírus no indivíduo. Neste individuo irá ocorrer a replicação, causando os sintomas da doença e o ciclo termina quando um novo mosquito ingere o sangue contaminado que posteriormente irá inocular esses microrganismos em outro indivíduo saudável (Figueiredo, 2007). São classificados em cinco famílias virais: Bunyaviridae, Togaviridae, Flaviviridae, Reoviridae e Rhabdoviridae (Avaelino, 2017; Lopes, 2014). Os arbovírus possuem uma distribuição geográfica baseada em condições ecológicas favoráveis aos vetores e hospedeiros, por conta disso têm ganhado visibilidade e destaque de importância principalmente em zonas tropicais por terem tido um aumento da população de mosquitos em áreas com mudanças ambientais (Lopes, 2014).

A modificação e interferência de ecossistemas por conta da globalização, ações humanas, crescimento populacional urbano e mudanças climáticas também afetam na permanência dos mosquitos em áreas que tornam suscetíveis a transmissão das arboviroses (Donalisio, 2017; Lima, 2016). A movimentação mundial da população de maneira voluntária como trabalho, intercâmbios escolares, lazer, entre outros, ou de maneira forçada por guerra e desastres ambientais colaboram para o transporte de patógenos por distâncias longas, podendo haver a levada de novos sorotipos ou até mesmo o patógeno para uma área que ainda não havia essa contaminação ou tinha sido erradicada (Lima, 2016).

O Brasil tem em sua maior parte um clima tropical sendo assim, um local propício para o ciclo dos mosquitos que transmitem as arboviroses (Lopes, 2014). O aquecimento global influencia diretamente no ciclo do mosquito, pois o aumento das temperaturas diminui o tempo de desenvolvimento das larvas e fazem com que o vírus também chegue mais rápido na glândula salivar do mosquito. Além disso, com os aumentos de temperatura há um aumento de área de transmissibilidade dos 
arbovírus, as zonas temperadas ficam mais quentes que o normal fazendo com que esses mosquitos passem a conseguir manter um ciclo nestas áreas (Lima, 2016). Por conta desses fatores que são rotineiramente visíveis, as arboviroses se tornam um problema de saúde pública, pois possuem grande taxa de dispersão, capacidade de adaptação a novos hospedeiros e ambientes (Vieira, 2019).

As barragens de contenção têm como objetivo maior, reter água de forma temporária e pode acumular resíduos, sedimentos e rejeitos de mineração, essas barragens acumulam resíduos por anos. As barragens que são para hidrelétrica elas retêm água, mas com finalidade de gerar energia, as de navegação e turismo formam grande lagos e garantem o nível da agua. (Redação AECweb / e-Construmarket) Os tipos de barragens construídos são do tipo convencional que o principal objetivo é a pesquisa e não convencional que inclui as barragens que são pouco utilizadas. No Brasil temos algumas construções de ambas. (Costa, 2012). Dentre as convencionais estão as barragens da terra que são constituídas por solo e tem dois subgrupos, homogênea que quando se tem predominância de um único material e zonadas que é feito zoneamento de materiais terrosos em função da permeabilidade. (Costa, 2012), a barragem de enrocamento é feita pela predominância da vedação da água. (Costa, 2012), as barragens de concreto que existem 5 tipos: gravidade que é feita inteiramente de concreto com pouca armação, é trabalhado apenas na compressão, a de gravidade aliviada que são estruturas mais leves, em contraforte que são estruturas ainda mais leves e apresenta o menor volume de concreto, as de concreto compactas onde o concreto é espalhado por tratores, abóbada são as de dupla curvatura, geralmente usadas para objetivos hidrelétricos. (Costa, 2012) e por último a barragem mista que possuem em sua constituição diferentes matérias normalmente de terra, enrocamento e concreto. (Costa, 2012)

Segundo Conselho Nacional de Meio Ambiente (CONAMA) em sua Resolução no 01/86, impacto ambiental é "qualquer alteração de propriedades, físicas, químicas, biológicas do meio ambiente, causado por qualquer forma de matéria ou energia resultante de atividades humanas que, direta ou indiretamente afetam a: saúde, o bem-estar da população; as atividades sociais e econômicas; a biota; as condições estéticas e sanitárias do meio ambiente; a qualidade dos recursos ambientais" (Brasil, 2019).

A construção de barragens promove diversos impactos tanto ambientais quanto na realidade social, induzindo a comunidade se adaptar as novas condições. As consequências de construções destas barragens podem ser tanto positivas quanto negativas. Dentre as positivas estão: desenvolvimento regional; criação de empregos na agricultura, pela irrigação de terras; nas indústrias que dependem de suas águas; aumento de renda com o lucro de exportações e excedentes agrícolas, de produtos industrializados ou da própria eletricidade. Dessa forma, trazem benefícios apenas para o setor econômico, mas em contrapartida, causam grandes impactos ambientais e sociais que representam custos para a sociedade. Tem-se a inundação de áreas extensas com grande diversidade biológica, intensificação de fluxos migratórios, inicialmente atraindo mão de obra e depois do encerramento das atividades, há demissão de operários. Comunidades ribeirinhas as jusantes das barragens são afetadas, devido ao seu meio de subsistência e acesso aos recursos do rio serem afetados pela alteração do escoamento do rio e da fragmentação do ecossistema (Pimentel, 2004).

Em 5 de novembro de 2015 a barragem de Fundão que pertencia a Samarco Mineração S.A rompeu despejando 47,3 milhões de $\mathrm{m}^{3}$ de rejeitos no meio ambiente, estes rejeitos causaram um caminho de destruição ao meio ambiente e chegando ao Rio Doce, mataram inúmeras espécies de animais pelo caminho, no solo e no Rio Doce. Além do impacto ambiental, houve também o impacto social, pessoas ficaram desabrigadas, houve 19 mortes e milhares de ribeirinhos ficaram sem o abastecimento de água, pois a bacia hidrográfica do Rio Doce, que foi contaminada pela lama, abrange 230 municípios, não somente de Minas Gerais como também do estado do Espírito Santo (Schuquel, 2019).

A barragem de brumadinho se rompeu no dia 25 de Janeiro de 2019, a barragem da mina localizada no complexo do Córrego do feijão, o que se sabe é que as sirenes da mineradora não tocaram no momento do rompimento causando uma tragédia muito maior do que poderia ter sido se tivessem tocado. A lama da barragem atingiu o rio Paraopeba e a área atingida 
pela lama corresponde a 290,14 hectares (Santos, 2019). Até o dia 30 de agosto de 2019 as buscas por vítimas do rompimento ainda ocorrem, neste dia foi encontrado mais uma vítima fatal resultando em 249 o número de mortos e 21 pessoas continuam desaparecidas (Brasil, 2019).

No dia 29 de Setembro foi encontrado mais um corpo, que se concretizou ser de um homem, sendo atualizados os dados para 250 o número de mortos, no dia 19 de novembro de 2019 um corpo foi achado a 3 metros de profundidade, sendo 251 o número de mortos e ainda seguem mais 19 desaparecidos. (Freitas, 2019). Diante disso, o presente estudo visa rtealizar um levantamento bibliográfico de relatórios do aumento de casos de Febre Amarela, Chickungunya, Dengue e Zika após o rompimento das barragens de Mariana e Brumadinho (Minas Gerais).

\section{Metodologia}

O presente estudo caracteriza-se como uma revisão bibliográfica, fundamentada a partir de estudos que discorrem sobre hipóteses do aumento da incidência de casos de Febre Amarela, Dengue, Zika e Chukungunya, relacionadas a ruptura das barragens em Minas Gerais. A revisão deu-se a partir das seguintes fases de desenvolvimento: identificação do tema, a partir da qual, delineou-se que perspectiva seria executada a proposta inicial de estudo: formulação da questão de pesquisa, caracterizada por estabelecer a execução do tema proposto, bem como a sua relevância para a comunidade científica; elaboração dos critérios de inclusão e exclusão de artigos, definição criteriosa dos filtros de pesquisa, de modo a restringir o campo de busca, promovendo a significação dos estudos mais relevantes; construção de instrumentos para coleta de dados relevantes dos artigos encontrados; consulta e busca e seleção dos Descritores de busca nas bases de dados e plataformas de acesso; avaliação e analise dos artigos selecionados na pesquisa; escolha do produto teórico para apresentação do estudo; interpretação e discussão dos resultados obtidos, a partir da qual discorreu-se acerca do produto técnico do trabalho, assim como a apresentação dos resultados obtidos e gerados após a seleção manual; apresentação da revisão juntamente com referencial teórico acerca do tema em questão, onde refinou-se os dados apresentados na pesquisa para a versão final.

O levantamento do material obtido na literatura para registro dos resultados foi realizado no período de maio a junho de 2020. As bases de dados utilizadas na triagem de material, foram as plataformas de busca: Nature, Medical Literature Analysis and Retrieval System Online (Medline), Science Direct e BVS, o estudo conferiu prioridade a trabalhos publicados na língua portuguesa.

\section{Resultados e Discussão}

A febre amarela no Brasil se apresenta em ciclos silvestres, entre 2000 e 2009, observou-se a expansão geográfica do ciclo da febre amarela e em 2014 houve uma reemergência nas regiões sudeste e Centro-oeste (Tabela 1). 
Tabela 1. Número de casos notificados de Febre Amarela de 2008 a 2019 no Brasil e Região Sudeste.

\begin{tabular}{ccccccc}
\hline $\begin{array}{c}\text { Período de } \\
\text { Análise }\end{array}$ & Brasil & Sudeste & MG & ES & SP & RJ \\
\hline $\begin{array}{c}\text { SET/2008- } \\
\text { SET/2009 }\end{array}$ & 47 & $\mathrm{X}$ & $\mathrm{X}$ & $\mathrm{X}$ & 28 & $\mathrm{X}$ \\
$\begin{array}{c}\text { SINAN } \\
\mathbf{2 0 1 0}\end{array}$ & 2 & 0 & 0 & 0 & 0 & 0 \\
$\begin{array}{c}\text { SINAN } \\
\mathbf{2 0 1 1}\end{array}$ & 2 & 0 & 0 & 0 & 0 & 0 \\
$\begin{array}{c}\text { JUL/2012- } \\
\text { JUN/2013 }\end{array}$ & 282 & 143 & 19 & 12 & 111 & 0 \\
$\begin{array}{c}\text { JUL/2014- } \\
\text { JUL/2015 } \\
\text { DEZ/2016- } \\
\text { MAR/2017 }\end{array}$ & 344 & $\mathrm{X}$ & $\mathrm{X}$ & $\mathrm{X}$ & $\mathrm{X}$ & $\mathrm{X}$ \\
$\begin{array}{c}\text { JUL/2017- } \\
\text { JUN/2018 }\end{array}$ & 7518 & 1483 & 1158 & 297 & 25 & 3 \\
$\begin{array}{c}\text { JUL/2018- } \\
\text { JUN/2019 }\end{array}$ & 682 & 481 & 74 & 27 & 345 & 35 \\
\hline
\end{tabular}

X: Sem notificação documentada

0 : Notificação equivalente a zero casos.

Fonte: SINAN e Ministério da Saúde- Boletins Epidemiológicos 2012 a 2019.

O primeiro registro de caso autóctone da Febre Chikungunya no Brasil ocorreu em 2014, no Estado do Amapá, na cidade de Oiapoque. Assim, Amapá, Bahia e Pernambuco são os que mais notificam casos no País. Dessa forma os casos de Febre Chikungunya foram notificados a partir de 2014. (Tabela 2).

Tabela 2. Número de casos notificados de Chickungunya de 2014 a 2019 no Brasil e Região Sudeste.

\begin{tabular}{|ccccccc}
\hline Período de Análise & Brasil & Sudeste & MG & ES & SP & RJ \\
SE52/2014 & 3.193 & $\mathrm{X}$ & $\mathrm{X}$ & $\mathrm{X}$ & $\mathrm{X}$ & $\mathrm{X}$ \\
SE52/2015 & 20.661 & $\mathrm{X}$ & $\mathrm{X}$ & $\mathrm{X}$ & $\mathrm{X}$ & $\mathrm{X}$ \\
\hline SE52/2016 & 277.882 & 25.245 & 1.452 & 470 & 4.807 & 18.516 \\
SE52/2017 & 185.737 & 22.984 & 16.771 & 841 & 1.084 & 4.288 \\
SE52/2018 & 68.962 & 52.966 & 11.761 & 670 & 810 & 39.725 \\
SE34/2019 & 110.627 & 82.510 & 2.645 & 1.286 & 1.803 & 76.776 \\
\hline
\end{tabular}

$\mathrm{X}$ : Sem notificação documentada.

Fonte: Ministério da Saúde- Boletins Epidemiológicos 2014 a 2019.

Observa-se que os casos de dengue no Brasil que entre 2009 a 2019 os anos com maiores índices são os anos de 2013, 2015, 2016 e 2019. Os anos de 2009 e 2010 não possuem muitas notificações podendo ser por negligência por parte de notificações (Tabela 3). 
Tabela 3. Número de casos notificados de Dengue de 2009 a 2019 no Brasil e Região Sudeste.

\begin{tabular}{|ccccccc|}
\hline $\begin{array}{c}\text { Período de } \\
\text { análise }\end{array}$ & Brasil & Sudeste & MG & ES & SP & RJ \\
\hline SINAN 2009 & 109.973 & $\mathrm{X}$ & 22.040 & $\mathrm{X}$ & $\mathrm{X}$ & $\mathrm{X}$ \\
\hline SINAN 2010 & 138.927 & $\mathrm{X}$ & 107.950 & $\mathrm{X}$ & $\mathrm{X}$ & $\mathrm{X}$ \\
\hline Jan-Abr 2011 & 507.798 & 233.943 & 25.853 & 22.176 & 79.477 & 106.437 \\
\hline Jan-Abr 2012 & 286.011 & 103.687 & 14.006 & 5.560 & 19.670 & 80.160 \\
\hline SE47/2013 & 1.143 .331 & 914.055 & 414.758 & 67.173 & 220.072 & 2012.052 \\
\hline SE47/2014 & 572.308 & 306.890 & 58.310 & 18.804 & 22.339 & 7.437 \\
\hline SE48/2015 & 1.587 .080 & 997.268 & 182.416 & 29.831 & 722.352 & 62.669 \\
\hline SE49/2016 & 1.487 .924 & 1.384 .752 & 522.022 & 40.760 & 739.418 & 82.552 \\
\hline SE50/2017 & 249.059 & 50.999 & 28.162 & 6.810 & 13.027 & 10.335 \\
\hline SE49/2018 & 247.393 & 68.460 & 27.241 & 9.162 & 17.704 & 14.353 \\
\hline SE34/2019 & 1.439 .471 & 999.178 & 471.165 & 59.318 & 437.047 & 31.648 \\
\hline
\end{tabular}

X: Sem notificação documentada

Fonte: Ministério da Saúde- Boletins Epidemiológicos (2017 a 2019)

A transmissão do Zika no Brasil foi confirmada em 2015 e até o boletim epidemiológico da semana 18, haviam 18 estados com diagnóstico laboratorial de Zika, passando para 22 estados até a semana epidemiológica 2 de 2016 (Brasil, 2015 ; Brasil, 2016). Os casos de Zika ganharam visibilidade por estarem associados a complicações neurológicas principalmente em recém-nascidos no ano de 2015. Sendo majoritariamente associado à microcefalia e em seguida ao desenvolvimento da síndrome de Guillain Barré. Em julho de 2015 foram notificados 58 casos de complicações neurológicas, sendo 29 que recebeu diagnóstico de síndrome de Guillain Barré e destes 29, 19 deles mostraram infecção antecedente por ZIKV (Tabela 4) (WHO, 2016).

Tabela 4. Número de casos notificados de Zika de 2016 a 2019 no Brasil e Região Sudeste.

\begin{tabular}{ccccccc}
\hline Período de Análise & Brasil & Sudeste & MG & ES & SP & RJ \\
& & & & & & \\
\hline SE52/2016 & 216.207 & 92.937 & 13.865 & 2.333 & 5.210 & 71.529 \\
SE52/2017 & 17.593 & 3.937 & 723 & 349 & 309 & 2.556 \\
SE52/2018 & 8.680 & 3.149 & 187 & 259 & 354 & 2.349 \\
\hline SE34/2019 & 9.813 & 3.980 & 888 & 622 & 900 & 1.570 \\
\hline
\end{tabular}

Fonte: Ministério da Saúde- Boletins Epidemiológicos (2017 a 2019) 


\section{Discussão}

O vírus da febre amarela é dito como um vírus antigo no Brasil, portando se levar em conta o período de estudo epidemiológico deste trabalho, o país já havia passado por surtos anteriores. Mas foi em 2016 que houve um dos piores surtos em muitos anos especialmente na região sudeste em um período bem próximo ao rompimento da barragem de Mariana- MG. A bióloga do Fiocruz Márcia Chamé (Fato. 2017) levantou a hipótese por ter analisado que o índice de notificações foi observado nas áreas próximas ao Rio Doce, principalmente nas localidades afetadas pela lama da barragem de Fundão. A bióloga afirma que a tragédia pode ter levado a aproximação dos macacos ao homem. Há também indícios de uma quebra na cadeia alimentar que afetou diretamente nos fatores naturais que mantinham o controle da população dos mosquitos.

Entre o intervalo do rompimento da primeira barragem e da segunda, o Sudeste ainda teve um grande índice de casos de Febre Amarela, no entanto, com maiores números no estado de São Paulo. A barragem de Córrego do Feijão em Brumadinho-MG rompeu em Janeiro de 2019, analisando o cenário que houve após a tragédia de Mariana, é de se esperar que os casos de Febre Amarela voltem a crescer no estado de Minas Gerais. Até junho de 2019 foram notificados 537 casos novos de Febre Amarela.

A tabela de dados de ZIKV se inicia com dados de 2016, que já podem ser contabilizados casos elevados em Minas gerais comparados aos anos seguintes. Em 2016 foi visto um crescimento ligado a barragem de Mariana e nos anos seguinte, começaram a aparecer nos índices um processo de estabilização de casos. No ano de 2019 é possível ver que ainda na Semana Epidemiológica, o número de casos notificados se aproxima ao número de notificações da Semana Epidemiológica 52 de 2017 e 2018 (Boletim Epidemiológico Volume 50, 2019). O que coincide o aumento com o rompimento da Barragem de Brumadinho ainda no início do ano de 2019.

Na tabela de dengue mostra que tem mais incidência de casos são os anos de 2013, 2015, 2016 e 2019. Em 2015, ano em que aconteceu o rompimento da barragem de Mariana, foram notificados 1.587.080 casos no Brasil. O sudeste foi a região que mais apresentou casos de dengue em relação ao ano anterior com um número de 997.268 casos, o estado de Minas Gerais teve 182.416 casos de dengue que é um número bem expressivo em relação aos anos anteriores e o estado de São Paulo teve um aumento exorbitante de 722.352 casos no estado, esse aumento pode se dar pela migração do mosquito já que seu habitat natural em que morava havia sido destruído com o rompimento da barragem de Mariana em Minas Gerais e com isso os mosquitos migraram para regiões urbanas próximas, o êxodo rural que acontece nesse local é um fator importante para esse aumento pois as pessoas infectadas com vírus estão em um novo lugar, sendo o mosquito que migrou também passa a transmitir.

O embate causado na região de Mariana afetou o rio Gualaxo que o mesmo deságua no rio doce e sofreu um enorme impacto, espécies aquáticas que se encontravam ali, não sobreviveram com todo esse choque, pois a lama tomou de conta e com isso o desequilíbrio ambiental do local, a proliferação do mosquito se dá também porque o predador dele não se encontra mais ali e então ele se reproduz com facilidade. $\mathrm{O}$ ano seguinte do rompimento o estado de Minas Gerais e São Paulo foram os estados com mais notificações, o estado do Espírito Santo teve um aumento com mais de 10 mil novos casos no ano de 2016.

Em 25 de janeiro de 2019 ocorreu o acidente na barragem de Brumadinho, que fica localizada em Minas Gerais, e consequentemente os números de casos de dengue teve um aumento com mais de $80 \%$ na região sudeste, isso ocorre devido a destruição das florestas ali presente, que são habitat natural do mosquito. No sudeste foram notificados durante a semana 34 999.178 casos de dengue enquanto que em 2018 na semana 49 foram registrados 68.460 no sudeste inteiro, em minas gerais nessa mesma semana epidemiológica foram 27.241 casos, já em 2019 na semana 34 foram 471.165 casos de dengue, foi mais ou menos 17 vezes mais, isso significa um alerta muito grande pois não foi o único estado a apresentar isso, no decorrer do ano de 2019 ocorreu o rompimento da barragem de Brumadinho-MG e consequentemente houve um aumento expressivo no 
número de casos, foram notificados 1.439.471 casos no brasil, no sudeste 999.178 casos e em Minas Gerais 471.165 casos e de acordo com esses dados é possível estabelecer que é o estado é o que mais tem casos na região estudada.

Uma prevenção muito boa contra o mosquito seria a vacina, que protegeria o indivíduo melhor, hoje no mercado existe uma vacina, Denguevaxia, que serve para os quatro sorotipos, porém só tem $60 \%$ de eficácia e para ter resultados, é recomendável que seja utilizada em três doses com intervalos de seis meses. Essa vacina tem mais eficácia no sorotipo DENV1 com 86,3\% porém a mesma não é gratuita e custa em torno de 100 reais em laboratórios especializados. Tem outra vacina que está sendo produzida no Brasil pelo instituto Butantan em parceria com institutos nacionais de saúde dos Estados Unidos, é uma vacina com vírus vivos atenuados, fracos através da deleção de fragmentos gênicos dos quatro tipos de vírus e que está na fase III do processo, recentemente o instituto brasileiro emitiu uma nota declarando que a vacina será de dose única e terá 17 mil voluntários após isso será submetida a Agência Nacional de Vigilância Sanitária (Anvisa), sendo aprovada será distribuída pelo sistema único de saúde (SUS). (Kruczewski, 2017; Butantan, 2019; Oliveira, 2016).

A tabela com os dados de CHIKV inicia em 2014, o ano em que ocorreu o início de casos autóctones no Brasil e foram notificados 3.193 casos, os anos de 2016, 2017, 2018 e 2019 foram os que mais apresentaram casos notificados no Brasil. No ano de 2016, na semana epidemiológica 52 é possível observar o grande número de casos de febre Chikungunya no Sudeste, depois de um ano do rompimento da barragem em Mariana-MG. Neste mesmo ano foram notificados 277.882 casos no Brasil, 25.245 casos no Sudeste e 1.452 casos em Minas Gerais. Pode se observar também aumento de casos no Rio de Janeiro, São Paulo e Espírito Santo, os quais são próximos de Minas Gerais. Em 2019, o ano em que ocorreu o rompimento da barragem em Brumadinho-MG, houve um aumento expressivo no número de casos, foram notificados 110.627 casos no Brasil, 82.510 no Sudeste e 2.645 casos em Minas Gerais. Na região Sudeste, o estado que apresentou o maior número de casos notificados foi o Rio de Janeiro com 76.776 casos.

É notório o expressivo aumento de casos de febre Chikungunya no ano de 2016 e 2019, este aumento de casos está relacionado ao descontrole de mosquitos infectados após o rompimento das duas barragens. E pode-se observar que há um grande aumento de casos em estados próximos de Minas Gerais, principalmente o Rio de Janeiro. A perda da fauna, proliferação de vetores que causam sérias doenças para a população e rios contaminados, são consequências ambientais de tragédias de Mariana e Brumadinho. Segundo Professor Côrtes, a lama depois de seca, promove uma forte impermeabilização do solo e mata a camada superficial biologicamente ativa. Assim, a germinação e o florescimento de espécies nativas ficam prejudicados e pode haver falta de alimentos para a fauna da região. A ausência de alimento pode causar morte e migração de animais, sendo assim, animais e vetores migram para outras regiões próximas em busca de alimentos (Cortês, 2019).

Isto explica os aumentos de infecção por Febre Amarela, Zika Vírus, Dengue e Chikungunya em Estados próximos de Minas Gerais. Portanto, o risco que as tragédias trazem para os surtos das arboviroses pode ser explicado pela migração de animais e pessoas das áreas afetadas pela lama para centros mais populosos. Semelhante aos ciclos da Febre Amarela. Tendo em vista as situações consequentes dos desastres, as pessoas que ficaram sem residência, animais que tiveram seu habitat modificado, todos precisam se locomover em busca de novos recursos, sendo assim, um acontecimento propício para a transmissão.

A prevenção mais eficaz para combater o aumento de casos de Febre Chikungunya, Dengue e Zika é a eliminação do vetor Aedes Aegypti. Evitar criadouros do mosquito, eliminando água armazenada como em vasos de plantas, pneus e piscinas sem manutenção. É importante usar repelentes e telas mosquiteiros em janelas (Brasil, 2019). Dessa forma, foi possível evidenciar que são de extrema importância a conscientização e atuação da população para combater a proliferação do Aedes Aegypti. O Ministério da Saúde desenvolve campanhas de informação, ações de combate ao vetor, porém, essas ações devem ser feitas em todas as cidades, principalmente em áreas com saneamento básico precário e de difícil acesso, com população carente de informações. 


\section{Conclusão}

Foi possível evidenciar o aumento do índice de arboviroses após os rompimentos das barragens de rejeitos em Mariana e Brumadinho no estado de Minas Gerais. O número de casos elevados em Minas Gerais no ano de 2016 e 2017 e também nos estados próximos. Ainda no final de 2017 e 2018 foram notórios esses casos diminuindo em notificação e quase chegando as notificações semelhantes aos anos anteriores do rompimento de Mariana. Porém, com o rompimento de Brumadinho em janeiro de 2019, é possível notar já nos índices de 2019 que os casos começaram a crescer novamente, chegando a alcançar números de notificações próximas ao ano inteiro de 2018.

Em relação a este problema as maneiras de evitar que o problema venha a ocorrer novamente seguem duas linhas de solução. Para as arboviroses a ampliação e maior incentivo na vacinação para febre amarela que é a única das quatro arboviroses estudadas que possui vacina na rede pública. Quanto às outras arboviroses, segue sendo como profilaxia o combate aos mosquitos transmissores, o incentivo às campanhas e diminuição dos focos de água parada que contribui para o ciclo do mosquito, pois a fêmeas põem os ovos em locais que possam armazenar água e por volta de 7 a 9 dias as larvas dão origem aos mosquitos (Secretaria de Saúde, 2019). O uso de repelentes também é uma maneira eficaz de prevenir que a fêmea faça o repasto sanguíneo para o amadurecimento dos ovos, que atacam ao amanhecer (Secretaria de Saúde, 2019).

Outra linha de solução para evitar o problema em questão é evitar o rompimento de barragens, passando desde ter uma fiscalização mais eficiente, visto que as barragens dão sinal de rompimento antes de acontecer. Foi sancionado o Projeto de Lei 3.676/16 que torna mais rígido a construção de barragens, o projeto põe como regra a proibição e passar a desativar as barragens feitas por alteamento a montante, valendo também para as que estão inativas que devem ser esvaziadas até 15 de Agosto de 2021. As barragens que estão ativas no modo a montante devem migrar para jusante em até três anos (Rodrigues, 2019.).

\section{Referências}

Alves, D. B. (2015) Uma regiao mineradora. minas gerais, Brasil, segunda metade do século XIX. Nuevo Mundo Mundos Nuevos. Nouveaux mondes -Novo Mundo. Mundos Novos- New world New worlds, 11 (37), 1119-1123.

Agência Nacional de Águas (ANA) (2016). Encarte Especial a Bacia do Rio Doce - Rompimento da Barragem em Mariana MG. 1 (1) 1-5.

Silva, V. L. V., Ramos, J. F (2017). Arboviroses e políticas públicas no Brasil / Arboviruses and public policies in Brazil. Revista Ciências em Saúde, 7 (3), 12.

Bernardy, K., Fagundes, L. S., Brandão, V. J., Keller L., Bortolini, J. G., Copatti, C. E. Impactos ambientais diante das catástrofes naturais - secas e queimadas. XVI Seminário Interinstitucional de Ensino, Pesquisa e Extensão Cruz Alta: Universidade de Cruz Alta; 2011,52 (7), $117-128$.

Conselho Nacional do Meio Ambiente (CONAMA) (2019). Resolução No 001, de 23/01/86. Dispõe sobre critérios básicos e diretrizes gerais para o Relatório de Impacto Ambiental 30 (57) 1-3.

Emergências em Saúde Pública de Importância Nacional (ESPIN) (2019). de Febre Amarela Silvestre em São Paulo e no Rio Grande do Sul e a Situação Epidemiológica Atual no Brasil (2008/2009). Febre Amarela Silvestre, Brasil 1-4.

Calvet, G. A., Santos, F. B., Sequeira, P. C (2016). Zika virus infection. Current Opinion in Infectious Diseases, 29 (5), 459-466.

Coelho, T (2012). Mineração e dependência no quadrilátero ferrífero. Revista Intratextos, 3 (1), 121-146.

Cortês, P. L (2019). Lições de Mariana não foram aplicadas em Brumadinho, dizem os especialistas. Instituto de Estudos Avançados da Universidade de São Paulo, São Paulo. Entrevista. htt://iea.usp.br/noticias/licoes-de-mariana-nao-foram-aplicadas-em-brumadinho-dizem-especialistas.

Costa, W. D (2012), Geologia de Barragens. Oficina dos textos.

Cunha, R. V., \& Trinta, K. S (2017). Chikungunya virus: clinical aspects and treatment -A Review. Mem. Inst. Oswaldo Cruz.112 (8), $523-531$.

Da Silva, C. P (2018). Um estudo bibliográfico acerca dos surtos de Febre Amarela no Brasil. Revista Brasileira de Meio Ambiente, 2 (1) 1-2.

Dias, M. (2014). Eventos Climáticos Extremos. Revista USP, 103 (22) 33-40.

Donalisio, M. R., Freitas, A. R. R., \& Zuben, A. P. B. V (2017). Arboviroses emergentes no Brasil: desafios para a clínica e implicações para a saúde pública. Rev. Saúde Pública, São Paulo, 51 (30), 121-129. 
Fialho, E. S (2013). Climatologia e Desastres Ambientais: A demanda dos recursos públicos após o espetáculo midiático, Rev. Tamoios, São Gonçalo. (RJ), 1, 42- 62 .

Figueiredo, L. T. M (2007). Emergent arboviruses in Brazil. Rev. Soc. Bras. Med. Trop. Uberaba, 40 (2), 224-229.

Freitas, C. M (2014). Desastres naturais e saúde: uma análise da situação do Brasil. Ciênc. saúde coletiva. 19 (9), 3645-3656.

Freitas, C. M., Silva, M. A., \& Menezes, F. C (2016). O desastre na barragem de mineração da Samarco: fratura exposta dos limites do Brasil na redução de risco de desastres. Cienc. Cult., São Paulo, 68 (3), 25-30.

Freitas, C. M., \& Ximenes, E. F (2012). Enchentes e saúde pública: uma questão na literatura científica recente das causas, consequências e respostas para prevenção e mitigação. Ciênc. Saúde coletiva, Rio de Janeiro, 17 (6), 1601-1616.

Kruczewski, B., Maestri C. M. E., Trevisan, G., \& Pastorello R. A (2017). Implantação da vacina da dengue no brasil: estudo situacional. Seminário de Iniciação Científica, Seminário Integrado de Ensino, Pesquisa e Extensão e Mostra Universitária, 14 (21) 497-501.

Lima, C. T. N (2016). Arboviroses emergentes e novos desafios para a saúde pública no Brasil. Rev. Saúde Pública. 50 (36) 179-183.

Lopes, N. A., Nozawa, C. E., Linhares, R. E. C (2014). Características gerais e epidemiologia dos arbovírus emergentes no Brasil. Rev Pan-Amaz Saude, 5 (3), $55-64$.

Madeira, T. J (2014). Caracterização geofísica e estrutural da principal estrutura mineralizada em ouro na região nordeste do Quadrilátero Ferrífero: Um guia para prospecção. Simpósio Brasileiro de Geofísica, 12 (1), 12-19.

Mascheretti, M (2013). Yellow fever: reemerging in the state of São Paulo.. Rev. Saúde Pública. 47 (5), 881-889.

Ministério da Saúde (2019). Combate ao Aedes Aegypti: prevenção e controle da Dengue, Chikungunya e Zika. Ministério da Saúde, 1(1) 1-2.

Ministério da Saúde (2014). Boletim epidemiológico. Aspectos epidemiológicos da febre amarela silvestre e a vigilância intensificada durante período de monitoramento, Brasil, 2012/2013, 52 (45) 1-5.

Ministério da Saúde (2019). Boletim Epidemiológico. Monitoramento do Período Sazonal da Febre Amarela Brasil - 2018/2019, 52 (51) 1-5.

Ministério da Saúde (2019). Boletim Epidemiológico. Monitoramento dos casos de arboviroses urbanas transmitidas pelo Aedes (dengue, chikungunya e Zika), Semanas Epidemiológicas 1 (34) 1-2.

Ministério da Saúde (2015). Boletim Epidemiológico. Monitoramento dos casos de dengue, febre de chikungunya e doença aguda pelo vírus Zika até a Semana Epidemiológica. 52 (46) 1-5.

Ministério da Saúde (2019). Boletim Epidemiológico. Monitoramento dos casos de dengue, febre de chikungunya e doença aguda pelo vírus Zika até a Semana Epidemiológica. 52 (47) 1-4.

Ministério da Saúde (2019). Boletim Epidemiológico. Monitoramento dos casos de dengue, febre de chikungunya e doença aguda pelo vírus Zika até a Semana Epidemiológica. 52 (50) 1-2.

Ministério da Saúde (2015). Boletim Epidemiológico. Monitoramento dos casos de dengue, febre de chikungunya e febre pelo vírus Zika até a Semana Epidemiológica 8, 45 (2) 1-3.

Ministério da Saúde (2015). Boletim Epidemiológico. Monitoramento dos casos de dengue, febre de chikungunya e febre pelo vírus Zika até a Semana Epidemiológica 45, (3) 1-4.

Ministério da Saúde (2018). Boletim Epidemiológico. Monitoramento dos casos de dengue, febre de chikungunya e febre pelo vírus Zika até a Semana Epidemiológica. 49 (2) 1-7.

Ministério da Saúde (2017). Secretaria de Vigilância em Saúde. Informe Especial Febre Amarela No Brasil. 1 (51) 1-2.

Mustafa, M. S., Rasotgi, V., Jain, S., \& Gupta, V. (2015). Discovery of fifth serotype of dengue virus (DENV-5): A new public health dilemma in dengue control. Medical Journal Armed Forces India, 71(1), 67-70.

Pimentel, V. C. R (2004). Alternativas de solução para os impactos físicos de barragens. São Paulo, 2004. Dissertação (Mestrado) - Escola Politécnica da Universidade de São Paulo - Departamento de Engenharia Hidráulica e Sanitária.

Presti, A., Lai, A., Cella, E., Zehender, G., \& Ciccozzi, M (2014). Chikungunya virus, epidemiology, clinics and phylogenesis: A review. Asian Pacific Journal of Tropical Medicine, 7(12), 925-932.

Riffel, E. S., Guasseli, L. A., \& Bressani, L. A (2016). Desastres associados a movimentos de massa: Uma revisão de literatura. Bol. Goia. Geogr., 36 (2), $285-306$.

Santos, V. S (2019). "Rompimento da barragem em Brumadinho"; Brasil Escola. https://brasilescola.uol.com.br/biologia/rompimento-barragembrumadinho.htm.

Shuquel, T (2019). Rompimento de Barragem traz à tona o desastre ambiental em Mariana. Metrópoles. Brasil. https://www. rompimento-de-barragem-traz- atona-o-desastre-ambiental-em-mariana. Acesso em Setembro/2019.metropoles.com/brasil/

Silva, G. P., \& Germani, G. I (2012). Política estatal e as transformações territoriais: analisando a construção da barragem de anagé - bahia - brasil. Revista Geográfica de América Central. 1 (1).

Simmons, C. P., Farrar, J. J., Chau, N., \& Wills, B (2012). Dengue. New England Journal of Medicine, 366 (15), 1423-1432. 
Research, Society and Development, v. 10, n. 1, e12110111529, 2021

(CC BY 4.0) | ISSN 2525-3409 | DOI: http://dx.doi.org/10.33448/rsd-v10i1.11529

SINAN. Ministério da Saúde- Sistema de Informação de Agravo de Notificação. Febre Amarela. Disponível em: http://portalsinan.saude.gov.br/.

Vieira, D. S (2019). Epidemiological profile of Zika, Dengue and Chikungunya virus infections identified by medical and molecular evaluations in Rondonia, Brazil. Rev. Inst. Med. trop. S. Paulo. 61 (40) 391-405.

World Health Organization. Dengue and Severe Dengue. Geneva: WHO, 2015. 